\title{
Canadian College of Neuropsychopharmacology 2019 award winners
}

\section{Heinz Lehmann Award}

Dr. Guy Rouleau is the recipient of the 2019 Canadian College of Neuropsychopharmacology (CCNP) Heinz Lehmann Award. Dr. Rouleau is a professor in the Department of Neurology and Neurosurgery at McGill University in Montreal, Quebec. He is also the director of the Montreal Neurological Institute and Hospital. The award is being given this year for basic research. The award, donated by Pfizer Canada Inc., consists of a $\$ 2000$ honorarium and a suitably engraved plaque. Congratulations to Dr. Rouleau!

\section{Innovations in Neuropsychopharmacology Award}

Dr. Cecilia Flores is the recipient of the 2019 CCNP Innovations in Neuropsychopharmacology Award. Dr. Flores is a professor in the Department of Psychiatry and an associate member of the Department of Neurology and Neurosurgery at McGill University in Montreal, Quebec. The award is being given this year for basic research. The award, donated by Pfizer Canada Inc., consists of a $\$ 2000$ honorarium and a suitably engraved plaque. Congratulations to Dr. Flores!

\section{CCNP Medal}

Dr. Lalit Srivastava is the recipient of the 2019 CCNP Medal. Dr. Srivastava is a full professor in the Department of
Psychiatry and an associate member in the Department of Neurology and Neurosurgery at McGill University in Montreal, Quebec. Dr. Srivastava has been active in the CCNP as a councillor, secretary and treasurer as well as in organizing meetings. This award, sponsored by the CCNP, consists of a bronze medal engraved with the name of the recipient. Congratulations to Dr. Srivastava!

\section{Young Investigator Award}

Dr. Vincenzo De Luca is the recipient of the 2019 Canadian College of Neuropsychopharmacology (CCNP) Young Investigator Award. Dr. De Luca is currently a scientist in the Molecular Brain Science Department at the Campbell Family Mental Health Research Institute at the Centre for Addiction and Mental Health (CAMH), a staff psychiatrist at CAMH and an associate professor in the Department of Psychiatry at the University of Toronto in Toronto, Ontario. The award is being given this year for clinical research. The award, donated by Pfizer Canada Inc., consists of a \$2000 honorarium and a suitably engraved plaque. Congratulations to Dr. De Luca!

These awards will be conferred at the 42nd Annual CCNP Meeting in Montreal, Quebec, June 12-15, 2019. The conference will be held in downtown Montreal at Thomson House.

DOI 10.1503/jpn.190080 